\title{
A new and expeditious synthesis of all enantiomerically pure stereoisomers of rosaprostol, an antiulcer drug
}

\author{
Wiesława Perlikowska, Remigiusz Żurawiński and Marian Mikołajczyk ${ }^{*}$
}

\section{Full Research Paper}

\section{Address:}

Department of Heteroorganic Chemistry, Centre of Molecular and Macromolecular Studies, Polish Academy of Sciences, Sienkiewicza 112, 90-363 Łódź, Poland

Email:

Marian Mikołajczyk* - marmikol@cbmm.lodz.pl

* Corresponding author

Keywords:

antiulcer drug; chiral resolution; rosaprostol; stereoselective

synthesis; synthetic design
Beilstein J. Org. Chem. 2016, 12, 2234-2239.

doi:10.3762/bjoc. 12.215

Received: 22 July 2016

Accepted: 28 September 2016

Published: 21 October 2016

Associate Editor: B. Stoltz

(C) 2016 Perlikowska et al.; licensee Beilstein-Institut. License and terms: see end of document.

\begin{abstract}
Four enantiomerically pure stereoisomers of rosaprostol (1), an antiulcer drug, were efficiently synthesized from the enantiomers of 2-(dimethoxyphosphoryl)-3-hexylcyclopentanone (3) as chiral substrates. The latter were obtained by resolution of racemic 3 with $(+)-(R)-1-(1-n a p h t h y l)$ ethylamine. The conversion of $(+)-3$ into rosaprostol stereoisomer (-)-1a was accomplished in four steps in $56 \%$ overall yield. According to the same protocol, the second stereoisomer (+)-1c was obtained from (-)-3 in 55\% overall yield. A slightly improved procedure of the last two steps of the transformation of $(+)-\mathbf{3}$ into $(-)-\mathbf{1 a}$ allowed an increase in the overall yield to $64 \%$. The remaining two stereoisomers, $(-)-\mathbf{1 b}$ and $(+)-\mathbf{1 d}$, were obtained from $(-)-\mathbf{1 a}$ and $(+)-\mathbf{1 c}$ in 71 and $68 \%$ yield, respectively, by a two-reaction sequence, in which a Mitsunobu inversion of configuration at C-5 was the key step.
\end{abstract}

\section{Introduction}

Rosaprostol (1) is a trade name for 7-(2-hexyl-5-hydroxycyclopentane)heptanoic acid (Figure 1) which belongs to a series of 19,20-dinorprostanoic acid derivatives. It exhibits gastric antisecretory activity and cytoprotective action without the undesired side effects common to other prostanoids like diarrhea, hypotension and uterine stimulation [1-8]. The sodium salt of 1 as a 1:1 mixture of the racemic 1,2-trans-1,5-cis and 1,2-trans-1,5-trans diastereoisomers has been marketed in Italy as Rosal for the treatment of gastric and duodenal ulcers
[9]. Because of the therapeutical importance, the synthesis of rosaprostol (1) has been attempted by many research groups in academia and industry. These include a patented synthesis of $\mathbf{1}$ starting from ricinoleic acid [10], and more efficient approaches to this mixture of racemic diastereoisomers of 1 [1117], two of which were developed by our group $[15,16]$.

Inspired by the trend in pharmaceutical sciences and industry to replace racemic by enantiomeric drugs (so-called "chiral shift") 


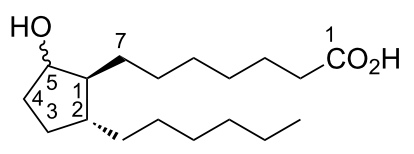

( \pm )- rosaprostol (1)

Figure 1: Structure of rosaprostol (1) and numbering system.

and as part of our research program on the synthesis and study of the stereostructure-bioactivity relationship in biologically active compounds [18,19], including selected prostanoids [2022], we decided to synthesize all four rosaprostol stereoisomers 1a-d in enantiomerically pure form (Figure 2). The two rosaprostol stereoisomers $\mathbf{1 c}$ and $\mathbf{1 d}$ have an absolute configuration at $\mathrm{C}-2$ of the cyclopentane ring opposite to that in natural prostaglandins of the A and $\mathrm{J}$ series. Therefore these compounds are expected to exhibit an increased biological stability as compared with $\mathbf{1 a}$ and $\mathbf{1 b}$, and to be more efficacious in the treatment of gastric ulcers [23].<smiles>O=C(O)CC1C(O)CC[C@@H]1O</smiles>

$(1 S, 2 R, 5 R)-1 \mathbf{a}$<smiles>CC1CCC(O)C1CNC(=O)O</smiles>

$(1 R, 2 S, 5 S)-1 \mathrm{c}$

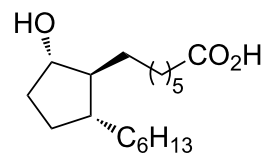

$(1 S, 2 R, 5 S)-1 b$

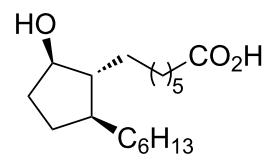

$(1 R, 2 S, 5 R)-1 \mathbf{d}$
Figure 2: The structures of stereoisomers of rosaprostol (1).

Recently we devised and reported the first strategy for the synthesis of the enantiomerically pure rosaprostol stereoisomers 1a-d using the diastereoisomerically pure camphor-protected 3-[(dimethoxyphosphoryl)methyl]-4,5-dihydroxycyclopent-2enones (-)-2a and (+)-2b as chiral building blocks (Scheme 1) [24]. These compounds can be prepared from optically inactive meso-tartaric acid through a two-step reaction sequence. It involves a complete desymmetrization during an acid-catalyzed reaction with $(+)$-camphor and methyl orthoformate and the subsequent treatment of the formed methyl diester with $\alpha$-phosphonate carbanion afforded diastereoisomeric ketals 2 in ca. $45 \%$ yield as a separable mixture.

According to this strategy, the starting substrate (-)-2a was converted into (-)-1a in nine steps in $18 \%$ overall yield. Then, the C-5 epimeric rosaprostol (-)-1b was prepared from (-)-1a in<smiles>COC12OC(C(=O)C=C1CP)C1CCC2(C)C1(C)C</smiles>

$(-)-2 \mathbf{a}$

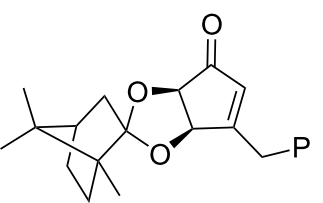

$(+)-2 b$

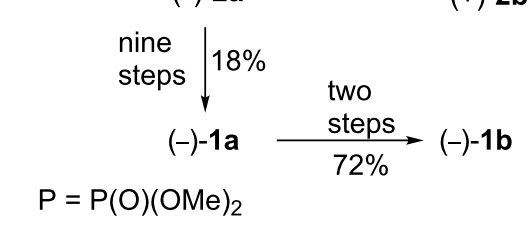

Scheme 1: Synthesis of stereoisomeric rosaprostols $1 \mathrm{a}$ and $1 \mathrm{~b}$ from $(-)-2 a$.

two steps in $72 \%$ yield (Scheme 1 ). The remaining two stereoisomers $\mathbf{1 c}$ and $\mathbf{1 d}$ could be obtained from $(+)-\mathbf{2} \mathbf{b}$, using the same sequence of reactions. Although our first synthesis allowed us to prepare the enantiomerically pure stereoisomers of rosaprostol $\mathbf{1}$ in a straightforward way, it was not fully satisfactory from the view point of efficiency and atom and step economy. Since a detailed evaluation of the biological activity and preclinical studies requires gram quantities of each stereoisomer of $\mathbf{1}$, we sought a shorter and more efficient approach to our targets.

Herein we disclose a new total synthesis of all enantiomerically pure rosaprostol stereoisomers $\mathbf{1 a}-\mathbf{d}$ in which we took advantage of our experience in the synthesis of racemic rosaprostol $(( \pm)-\mathbf{1})$ [15]. This synthesis is the most efficient among all reported syntheses of $( \pm)-1$ up to date [10-17]. As shown in Scheme 2, the conversion of a simple substrate, dimethyl methanephosphonate into $( \pm)-\mathbf{1}$ was achieved in only seven steps and in $42 \%$ overall yield. Racemic 2-dimethoxyphosphoryl-3-hexylcyclopentan-1-one (3) is the key intermediate in this synthesis. This report describes the resolution of $( \pm)-\mathbf{3}$ into its enantiomers and their application as starting chiral reagents for the preparation of rosaprostol stereoisomers 1a-d.

\section{Results and Discussion}

The total synthesis of stereoisomeric rosaprostols 1a-d commenced with the resolution of racemic 2-dimethoxyphosphoryl-3-hexylcyclopentan-1-one (3). Thus, a solution of $( \pm)-3$ in methylene chloride was reacted with $(+)-(R)-1-(1-$ naphthyl)ethylamine in the presence of dehydrating agents. The reaction mixture was stirred for five days at room temperature and after a usual work-up the crude mixture of diastereoisomeric condensation products $\left({ }^{31} \mathrm{P}\right.$ NMR assay, $\delta_{\mathrm{P}}=28.08$ and $28.16 \mathrm{ppm}$ ) was separated into pure components by column chromatography (hexane/acetone 15:1). All the spectral data in- 


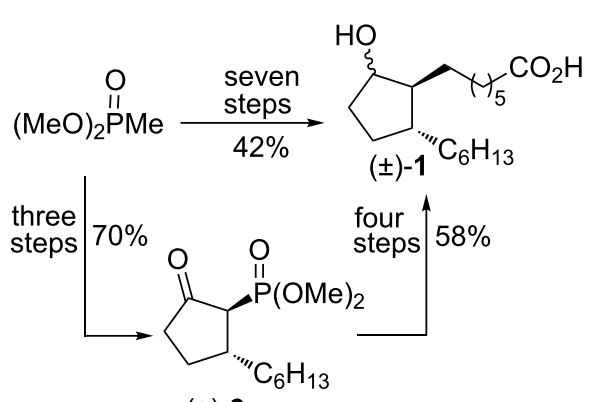

$( \pm)-3$

Scheme 2: Synthesis of racemic rosaprostol ( \pm-1$)$.

dicated that the isolated diastereoisomers $\mathbf{4 a}$ and $\mathbf{4 b}$ have the enamine and not imine structure that should be formed in the first reaction stage. Presumably, due to electron-withdrawing properties of the phosphoryl and carbonyl groups, the $\alpha$-methine hydrogen migrates to the imine nitrogen to form the cyclopent1-ene structure.

The pure diastereoisomers of $\mathbf{4}$ were then efficiently converted by hydrolysis under weakly acidic conditions into the corresponding enantiomerically pure cyclopentanones (+)-3 and $(-)-\mathbf{3}$ as the desired chiral starting materials in our new stereoselective synthesis of rosaprostols $\mathbf{1 a}-\mathbf{d}$. The resolution of $( \pm)-\mathbf{3}$ and some experimental details are depicted in Scheme 3. It shows also the absolute configurations of $(+)-\mathbf{3}$ and (-)-3 ascribed to the compounds based on their successful conversion into the known rosaprostols $\mathbf{1 a}$ and 1c, respectively.

Having successfully prepared the enantiomerically pure starting materials (+)-3 and (-)-3, we could proceed with the synthesis of the four stereoisomers of rosaprostol (1). The synthetic pathway to stereoisomers 1a and 1c is outlined in Scheme 4.

At first, the Horner olefination reaction of (+)-3 and (-)-3 with methyl 5-formylpentanecarboxylate was carried out. The use of a mixture of $\mathrm{Al}_{2} \mathrm{O}_{3}$ and $\mathrm{KOH}$ as a base in this reaction afforded the corresponding olefination products $(-)-(R)-\mathbf{5}$ and $(+)-(S)-\mathbf{5}$ in high yields. Both of them were formed as mixtures of $E$ and $Z$-isomers. Although these mixtures were directly used for further transformations, for characterization purposes they were separated by column chromatography. The $E / Z$ ratio in $(-)-(R)-5$ was determined by integration of the carbonyl carbon resonances in the ${ }^{13} \mathrm{C}$ NMR spectra $\left(\delta_{\mathrm{CO}}=209.09\right.$ and $207.79 \mathrm{ppm}$ for $(Z)-(R)-5$ and $(E)-(R)-5)$, while in the case of $(+)-(S)-5$ by integration of the vinylic ring carbon signals $\left(\delta_{(\mathrm{O}) \mathrm{CC}=\mathrm{C}}=139.72\right.$ and $136.18 \mathrm{ppm}$ for $(Z)-(S)-\mathbf{5}$ and $(E)-(S)-\mathbf{5}$, respectively). In the next step, the exocyclic carbon-carbon double bond was selectively reduced with sodium hydrogen

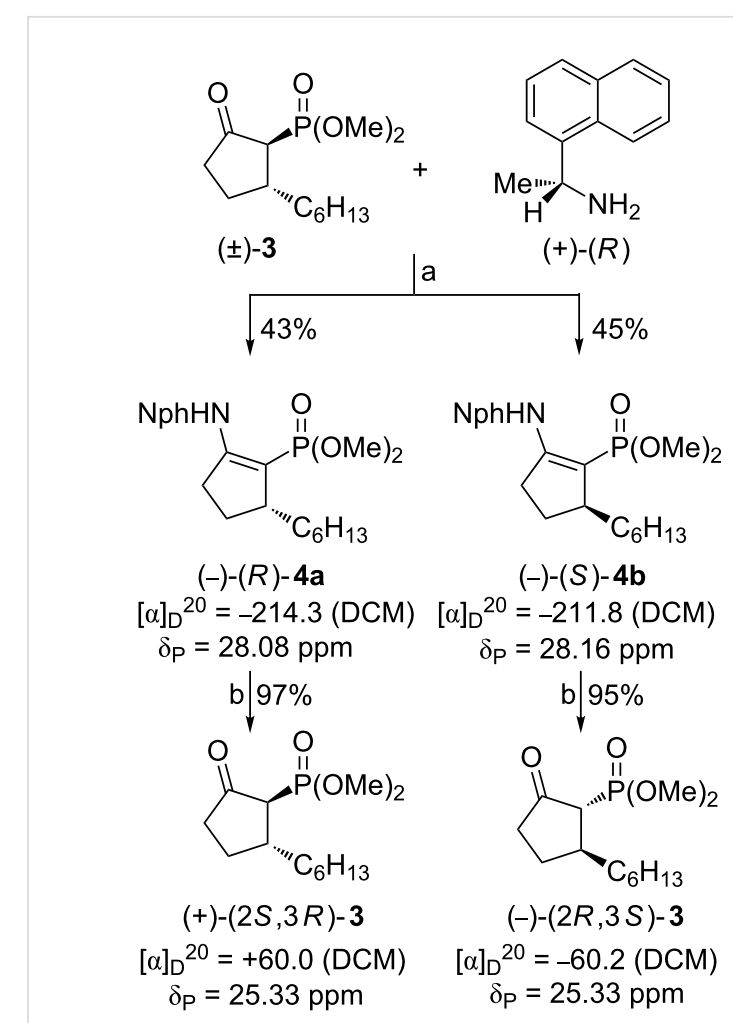

Scheme 3: Resolution of racemic cyclopentanone 3. Reagents and conditions: (a) $\mathrm{Al}_{2} \mathrm{O}_{3}, \mathrm{SiO}_{2}, \mathrm{MS} 5 \AA$, DCM, rt, $5 \mathrm{~d}$; (b) cation exchanger Dowex 50WX4, MeOH/ $\mathrm{H}_{2} \mathrm{O} 5: 1, \mathrm{rt}, 3 \mathrm{~N} \mathrm{HCl}$ (drops), column chromatography.

telluride to give the corresponding disubstituted cyclopentanone (+)-6 containing considerable amounts of the 1,2-cis isomer as revealed by ${ }^{13} \mathrm{C}$ NMR spectra displaying two carbonyl carbon signals $(\delta=221.2 \mathrm{ppm}$ for 1,2-trans isomer and $220.5 \mathrm{ppm}$ for 1,2-cis isomer). The reduction product was treated with $p$-toluenesulfonic acid in methanol for a few hours to give the desired $(+)$-trans -6 isomer contaminated with very small amounts $(4 \%)$ of the cis-isomer. Under the same reduction/epimerization conditions, $(+)-(S)-5$ was successfully transformed into (-)-trans-6 containing 7\% of the corresponding cis isomer. Alkaline hydrolysis of both enantiomeric methyl esters $(+)-6$ and (-)-6 afforded the ketoacids $(+)-7$ and (-)-7, respectively. As revealed by ${ }^{13} \mathrm{C}$ NMR spectoscopy, the first of them contained only $2 \%$ of the cis-ketoacid 7 , while in the levorotatory ketoacid 7 the content of the cis-isomer was slightly higher (7\%). In the final step, the ketoacid (+)-7 was reduced stereoselectively with L-Selectride under controlled temperature conditions $\left(-75{ }^{\circ} \mathrm{C}, 4 \mathrm{~h}\right)$ to give the desired stereoisomeric rosaprostol as a colorless solid (mp $\left.41-42{ }^{\circ} \mathrm{C}\right)$ exhibiting an optical rotation $[\alpha]_{\mathrm{D}}{ }^{20}=-61.0\left(\mathrm{CHCl}_{3}\right)$. All physicochemical properties and spectral data confirmed that the product formed in the above reaction is identical with the stereoisomer $(-)-(1 S, 2 R, 5 R)-1$ a prepared in our earlier work [23]. 


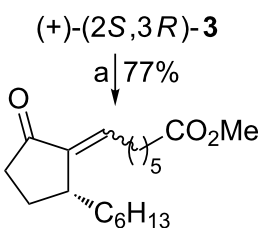

$(-)-(R)-5(E / Z=2.5: 1)$<smiles>CC(=O)NCC1C(=O)CC[C@@H]1[13CH3]</smiles>

$(+)-(1 S, 2 R)-6$ $[\alpha]_{\mathrm{D}}^{20}=+29.3(\mathrm{DCM})$

(for trans/cis $=96: 4$ )

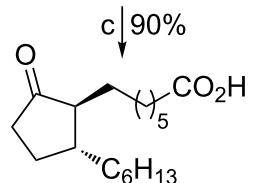

$(+)-(1 S, 2 R)-7$

$[\alpha]_{D}^{20}=+31.8\left(\mathrm{CHCl}_{3}\right)$

(for trans $/$ cis $=98: 2$ ) d $87 \%$

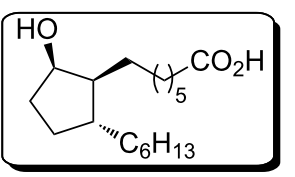

$(-)-(1 S, 2 R, 5 R)-1 \mathbf{a}$ $[\alpha]_{D}^{20}=-61.0\left(\mathrm{CHCl}_{3}\right)$

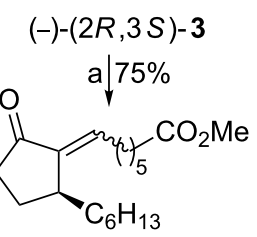

$(+)-(S)-5(E / Z=3: 1)$<smiles>COC(=O)NCC1C(=O)CCC1c1ccccc1</smiles>

$(-)-(1 R, 2 S)-6$

$[\alpha]_{\mathrm{D}}^{20}=-30.1(\mathrm{DCM})$

(for trans/cis $=93: 7$ )

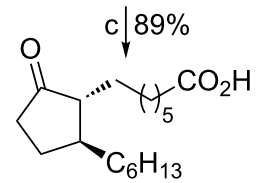

$(-)-(1 R, 2 S)-7$

$[\alpha]_{\mathrm{D}}{ }^{20}=-32.1\left(\mathrm{CHCl}_{3}\right)$

(for trans/cis $=93: 7$ )

d) $86 \%$

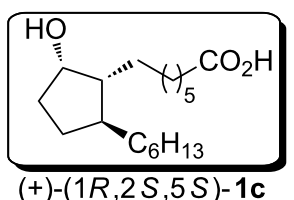

$[\alpha]_{D}^{20}=+60.1\left(\mathrm{CHCl}_{3}\right)$

Scheme 4: Synthesis of rosaprostol stereoisomers $1 \mathrm{a}$ and $1 \mathrm{c}$. Reagents and conditions: (a) $\mathrm{KOH} / \mathrm{Al}_{2} \mathrm{O}_{3}, \mathrm{OHC}\left(\mathrm{CH}_{2}\right)_{5} \mathrm{CO}_{2} \mathrm{Me}, \mathrm{C}_{6} \mathrm{H}_{6}$, $3 \mathrm{~h}$ rt; (b) Te, $\mathrm{NaBH}_{4}$, EtOH, 6 h, rt; (c) $1 \mathrm{~N} \mathrm{NaOH}$, EtOH, $3 \mathrm{~h}, 45^{\circ} \mathrm{C}$; (d) L-Selectride, THF, $-75^{\circ} \mathrm{C}, 4 \mathrm{~h}$.

In summary, the rosaprostol stereoisomer (-)-1a was synthesized from the starting cyclopentanone phosphonate $(+)-3$ in four steps and $56 \%$ overall yield. As expected, the reduction of the carbonyl group in the ketoacid (-)-7 by L-Selectride produced the second stereoisomer of rosaprostol (+)-1 c, $[\alpha]_{\mathrm{D}}{ }^{20}=+60.1\left(\mathrm{CHCl}_{3}\right)$. The overall yield of the four-step conversion of (-)-3 into (+)-1c was $54.5 \%$.

With regard to the assignment of the absolute configuration to $(+)-\mathbf{3}$, it is important to notice that (-)-1a obtained herein has the absolute configuration $R$ at the $\mathrm{C}-2$ stereogenic center. As the chirality at this carbon atom remains unchanged in the fourstep conversion of (+)-3 into (-)-1a, the same chirality has to be assigned to the corresponding carbon atom (now C-3) in (+)-3. Taking into account a trans-arrangement of the phosphoryl and $n$-hexyl substituents, the absolute configuration $(2 S, 3 R)$ should be ascribed to ( + )-3 according to Cahn, Ingold, and Prelog rules

$[25,26]$. As a consequence, the enantiomer $(-)-3$ has the absolute configuration $(2 R, 3 S)$.

In the course of our investigations on the synthesis of the stereoisomers 1a and 1c an alternative, more efficient method for the conversion of the enantiomeric methyl esters $\mathbf{6}$ into $1 \mathrm{a}$ or $1 \mathrm{c}$ was also elaborated as a two-reaction sequence. The first step comprises a reduction of 6 by L-Selectride at $-45^{\circ} \mathrm{C}$ affording the corresponding diol $\mathbf{8}$. In the second step, a selective air oxidation of the primary hydroxy group in $\mathbf{8}$ was carried out according to the procedure described by Rhee and coworkers [27] to give stereoisomeric $\mathbf{1}$. The transformation of (+)-6 into (-)-1a according to the new protocol is shown in Scheme 5. It is noteworthy that the overall yield of the synthesis of $(-)-\mathbf{1 a}$ from $(+)-\mathbf{3}$ involving this alternative procedure was increased to $64 \%$.

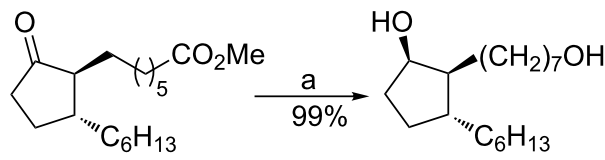

$(+)-(1 S, 2 R)-6$ $[\alpha]_{D}^{20}=+29.3(\mathrm{DCM})$

$(-)-(1 S, 2 R, 5 R)-8$

$[\alpha]_{D}^{20}=-67.7\left(\mathrm{CHCl}_{3}\right)$<smiles>O=C(O)CC1C(O)CC[C@@H]1O[Mg]</smiles>

$(-)-(1 S, 2 R, 5 R)-\mathbf{1 a}$ $[\alpha]_{\mathrm{D}}^{20}=-60.5\left(\mathrm{CHCl}_{3}\right)$

Scheme 5: Conversion of methyl ester (+)-6 into rosaprostol (-)-1a Reagents and conditions: (a) L-Selectride, THF, $-45^{\circ} \mathrm{C}, 3 \mathrm{~h}$; (b) $\mathrm{O}_{2}$ (air), $\mathrm{Pd} / \mathrm{C}, \mathrm{NaBH}_{4}, \mathrm{KOH}, \mathrm{H}_{2} \mathrm{O} / \mathrm{MeOH}$ 2:1.

With the two rosaprostol stereoisomers 1a and 1c in hand, the synthesis of the remaining two stereoisomers $\mathbf{1 b}$ and $\mathbf{1 d}$ was readily accomplished with a Mitsunobu reaction [28] inverting the configuration at C-5. In fact, $1 \mathbf{a}$ and $1 \mathbf{c}$ were obtained through a two-step sequence starting with the methylation of $(-)-1 a$ and $(+)-1 c$ followed by a one-pot Mitsunobu esterification-hydrolysis as shown in Scheme 6. In detail, treatment of rosaprostols (-)-1a and (+)-1c with diazomethane gave the corresponding rosaprostol methyl esters (-)-9 and (+)-9 in yields higher than $90 \%$. Then the esters 9 were subjected to a Mitsunobu esterification under standard conditions (THF, rt) using $p$-nitrobenzoic acid (PNBA), triphenylphosphine and diisopropyl azodicarboxylate (DIAD). The $p$-nitrobenzoic acid esters $(+)-\mathbf{1 0}$ and $(-)-\mathbf{1 0}$ formed in this reaction (not shown) 
were immediately hydrolyzed under basic conditions affording the two desired rosaprostol stereoisomers $(-)-\mathbf{1 b}$ and $(+)-\mathbf{1 d}$ in 71 and $68 \%$ yield, respectively.

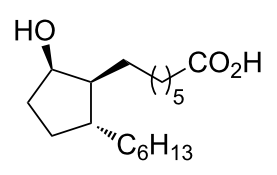

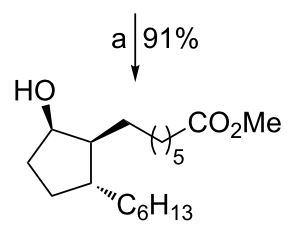

$(-)-(1 S, 2 R, 5 R)-9$ $[\alpha]_{D}^{20}=-65.0\left(\mathrm{CHCl}_{3}\right)$

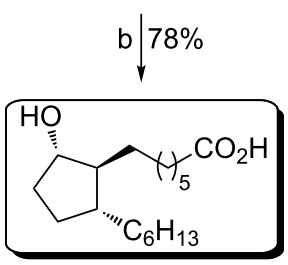

$(-)-(1 S, 2 R, 5 S)-\mathbf{1 b}$ $[\alpha]_{D}^{20}=-24.7\left(\mathrm{CHCl}_{3}\right)$
$(-)-(1 S, 2 R, 5 R)-\mathbf{1 a}$ $[\alpha]_{D}^{20}=-61.0\left(\mathrm{CHCl}_{3}\right)$

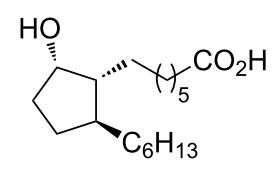

$(+)-(1 R, 2 S, 5 S)-1 \mathrm{c}$ $[\alpha]_{D}^{20}=+60.1\left(\mathrm{CHCl}_{3}\right)$

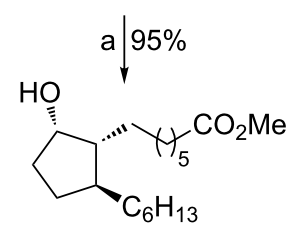

$(+)-(1 R, 2 S, 5 S)-9$ $[\alpha]_{D}^{20}=+64.0\left(\mathrm{CHCl}_{3}\right)$

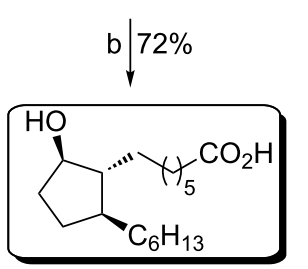

$(+)-(1 R, 2 S, 5 R)-1 \mathbf{d}$ $[\alpha]_{\mathrm{D}}^{20}=+25.0\left(\mathrm{CHCl}_{3}\right)$
Scheme 6: Synthesis of rosaprostol stereoisomers $\mathbf{1 b}$ and $\mathbf{1 d}$ Reagents and conditions: (a) $\mathrm{CH}_{2} \mathrm{~N}_{2}, \mathrm{Et}_{2} \mathrm{O},-30^{\circ} \mathrm{C}$; (b) i. PNBA, $\mathrm{Ph}_{3} \mathrm{P}$, DIAD, THF, rt; ii. LiOH, EtOH, rt, 24 h.

Finally, for the sake of completeness of our total synthesis of stereoisomeric rosaprostols $\mathbf{1}$, the $p$-nitrobenzoates $(+)-\mathbf{1 0}$ and $(-)-10$ were isolated and fully characterized (see Supporting Information File 1 for details).

\section{Conclusion}

In summary, a new concise and efficient synthesis of the four enantiomerically pure stereoisomers of rosaprostol (1), an antiulcer drug, was accomplished. The stereoisomers (-)-1a and $(+)-1 c$ were obtained from the enantiomeric 2-phosphoryl-3hexylcyclopentanones (+)-3 and (-)-3, respectively, in four steps in about $55 \%$ overall yield. The other two stereoisomers, $(-)-\mathbf{1 b}$ and $(+)-\mathbf{1 d}$, were prepared starting from (-)-1a and $(+)-1 \mathrm{c}$ in two steps in $70 \%$ yield. The present synthesis compares favorably in terms of the required steps (halved number) and efficiency (three-fold improvement in yield) with previous reports. It uses inexpensive reagents and operationally simple reactions. Because the synthetic sequence may be performed on a multigram-scale, it is suitable for preparation of sufficient amounts of material for biological and preclinical studies.

\section{Supporting Information}

\section{Supporting Information File 1}

Experimental procedures, spectral data and copies of the ${ }^{1} \mathrm{H},{ }^{13} \mathrm{C}$ and ${ }^{31} \mathrm{P}$ NMR spectra for compounds $\mathbf{1}$ and 3-10 are provided.

[http://www.beilstein-journals.org/bjoc/content/ supplementary/1860-5397-12-215-S1.pdf]

\section{Acknowledgements}

This work was financially supported by the Ministry of Science and Higher Education of Poland within grant no. NN 204 129737.

\section{References}

1. Valcavi, U.; Caponi, R.; Brambilla, A.; Palmira, M.; Minoja, F.; Bernini, F.; Musanti, R.; Fumagalli, R. Arzneim. Forsch. 1982, 32, 657-663.

2. Adami, M.; Scarpignato, C.; Signorini, G.; Coruzzi, G.; Bertaccini, G. Farmaco, Ed. Prat. 1984, 39, 409-416.

3. Fumagalli, R.; Caponi, R.; Corsini, A.; Brambilla, A.; Palmira, M.; Bernini, F.; Valcavi, U. Prostaglandins 1985, 29, 467-474. doi:10.1016/0090-6980(85)90104-2

4. Tincani, G. P.; Maniscalco, G.; Gunelli, M.; Ciarrocchi, V. Minerva Med. 1987, 78, 847-853.

5. Aly, A. Scand. J. Gastroenterol. 1987, 22, 43-49. doi:10.3109/00365528709089761

6. Di Murro, R.; Camarri, E.; Ciani, D.; Mariotti, L.; Nencioni, C.; Romagnoli, A. M. Int. J. Clin. Pharmacol. Res. 1988, 8, 345-351.

7. Ciprandi, G.; Ruffoni, S.; Ciani, D.; Tosca, M. A.; Canonica, G. W. Int. J. Immunol. 5, 81-84.

8. Calcamuggi, G.; Babini, G.; Arduino, C.; Lanzio, M.; Anfossi, G.; Ciani, D.; Emanuelli, G.

Adv. Prostaglandin, Thromboxane, Leukotriene Res. 1991, 21B, 789-792.

9. Lorencini, G. Drugs Future 1986, 11, 666-668. doi:10.1358/dof.1986.011.08.49450

10. Valcavi, U. 19,20-Bis-Nor-Prostansäuren, Verfahren zu ihrer Herstellung und sie enthaltende Arzneimittel. German Patent DE2535343, Feb 19, 1976.

11. Valcavi, U.; Innocenti, S.; Bosone, E.; Farina, P.; Marotta, V.; Zabban, G. B. Improved processes for preparing 7-(2-hexyl-5-hydroxy-cyclopentyl)-heptanoic acid. European Patent EP0155392, Sept 25, 1985.

12. Shono, T.; Kise, N. Tetrahedron Lett. 1990, 31, 1303-1306. doi:10.1016/S0040-4039(00)88791-2

13. Shono, T.; Kise, N.; Fujimoto, T.; Tominaga, N.; Morita, H. J. Org. Chem. 1992, 57, 7175-7187. doi:10.1021/jo00052a036

14. Tanimori, S.; Kainuki, T.; Nakayama, M. Biosci., Biotechnol., Biochem. 1992, 56, 1807-1809. doi:10.1271/bbb.56.1807

15. Mikołajczyk, M.; Żurawiński, R. J. Org. Chem. 1998, 63, 8894-8897. doi:10.1021/jo981120g

16. Mikołajczyk, M.; Mikina, M.; Jankowiak, A.; Mphahlele, M. J. Synthesis 2000, 1075-1077. doi:10.1055/s-2000-6316

17. Trost, B. M.; Pinkerton, A. B. J. Org. Chem. 2001, 66, 7714-7722. doi:10.1021/jo010593b 
18. Mikołajczyk, M.; Mikina, M.; Żurawiński, R. Pure Appl. Chem. 1999, 71, 473-480. doi:10.1351/pac199971030473

19. Mikołajczyk, M.; Bałczewski, P. Top. Curr. Chem. 2002, 223, 161-214. doi:10.1007/3-540-46100-0_6

20. Żurawiński, R.; Mikina, M.; Mikołajczyk, M. Tetrahedron: Asymmetry 2010, 21, 2794-2799. doi:10.1016/j.tetasy.2010.11.007

21. Łukasik, B.; Mikołajczyk, M.; Bujacz, G.; Żurawiński, R. Org. Biomol. Chem. 2015, 13, 807-816. doi:10.1039/C4OB01535E

22. Żurawinski, R.; Mikołajczyk, M.; Cieślak, M.; Królewska, K.; Kaźmierczak-Barańska, J. Org. Biomol. Chem. 2015, 13, 7000-7012. doi:10.1039/C5OB00550G

23. Das, S.; Chandrasekhar, S.; Yadav, J. S.; Grée, R. Chem. Rev. 2007, 107, 3286-3337. doi:10.1021/cr068365a

24. Łukasik, B.; Perlikowska, W.; Żurawiński, R.; Mikołajczyk, M. J. Org. Chem. 2015, 80, 9798-9802. doi:10.1021/acs.joc.5b01749

25. Cahn, R. S.; Ingold, C. K.; Prelog, V. Angew. Chem., Int. Ed. Engl. 1966, 5, 385-415. doi:10.1002/anie.196603851

26. Prelog, V.; Helmchen, G. Angew. Chem., Int. Ed. Engl. 1982, 21, 567-583. doi:10.1002/anie.198205671

27. An, G.; Ahn, H.; De Castro, K. A.; Rhee, H. Synthesis 2010, 477-485. doi:10.1055/s-0029-1217115

28. Mitsunobu, O. Synthesis 1981, 1-28. doi:10.1055/s-1981-29317

\section{License and Terms}

This is an Open Access article under the terms of the Creative Commons Attribution License (http://creativecommons.org/licenses/by/4.0), which permits unrestricted use, distribution, and reproduction in any medium, provided the original work is properly cited.

The license is subject to the Beilstein Journal of Organic Chemistry terms and conditions:

(http://www.beilstein-journals.org/bjoc)

The definitive version of this article is the electronic one which can be found at:

doi:10.3762/bjoc. 12.215 